\title{
PLANTAS EM MÃOS HABILIDOSAS E EM MODOS ESPECÍFICOS DE VER: UMA ETNOGRAFIA EM CENÁRIOS BOTÂNICOS ${ }^{1}$
}

\author{
PLANTS IN SKILLFUL HANDS AND \\ IN SPECIFIC WAYS OF SEEING: AN \\ ETHNOGRAPHY AT BOTANICAL \\ SCENARIOS
}

\section{Elizeu Pinheiro da Cruz}

elizeuprof@gmail.com

Doutor em Ciências Sociais pela Universidade Federal da Bahia (UFBA); Professor do Curso de Ciências Biológicas e do Programa de Pós-Graduação em Ensino, Linguagem e Sociedade (PPGELS) da Universidade do Estado da Bahia (UNEB)

ORCID: https://orcid.org/0000-0003-1454-6832

\section{RESUMO}

Ancorado nos estudos sobre as relações entre humanos e não humanos, este artigo aborda o trabalho de cortar dos biólogos relacionado à descrição da biodiversidade vegetal de territórios da Bahia, Brasil, a fim de produzir apontamentos que possam contribuir com as circularidades dos discursos ambientais contemporâneos, atentos à superação das dicotomias humanidade-natureza e indivíduo-ambiente. Ele é um desdobramento das notas de campo elaboradas em uma etnografia desenvolvida entre os anos $2011 \mathrm{e}$ 2016 que acompanhou, em laboratórios, matas e outros cenários das ciências biológicas da Universidade Estadual do Sudoeste da Bahia, movimentos de coletivos de plantas, animais, biólogos e outros entes em pesquisas voltadas para descrições da biodiversidade da Bahia como excepcionalidade. Cortar plantas é uma ação assumida pelos biólogos como possibilidade de composição, por multiplicação de formas, de descrições dos mundos habitados pelas plantas em traçados das ciências biológicas.

Palavras-chaves: Agenda das plantas. Corte. Diferença.

\begin{abstract}
Based on studies of human-nonhuman relation, this paper addresses the cutting work of biologists related to the description of plant biodiversity from territories in Bahia, Brazil, in order to produce notes that can contribute to the circulation of contemporary environmental speeches and which are attentive to the overcoming of the dichotomies humanity-nature and individual-environment. It is an unfolding of the field notes elaborated in an ethnography that was developed from 2011 to 2016 and that accompanied movements of collectives of plants, animals, biologists and other entities in laboratories, forests and other scenarios related to the biological sciences of the State University of the Southwest of Bahia and in researches which aimed at describing the biodiversity of Bahia as exceptional. Plant cutting is assumed by biologists as a possibility of composition, through forms of multiplication, of descriptions of the worlds inhabited by plants in tracts of the biological sciences.
\end{abstract}

Keywords: Agenda of Plants. Cut. Difference. 


\section{INTRODUÇÃO}

Localizado no conjunto de estudos sobre as relações entre humanos e não humanos (LATOUR, 2012), este texto trata de encontros de plantas, biólogos, estudantes de graduação e tesoura, em uma mata e em um laboratório, engajados na produção de pesquisas que descrevem diversidade e ocorrência de plantas e permitem tematizar a problemática ambiental na Botânica. No cenário multiespécie (TSING, 2019; KIRKSEY; HELMREICH, 2010) constituído na intersecção mata-laboratório, destaca-se a agência de atores humanos e não humanos como promotores de condições de possibilidade da produção científica situada, oposta à transcendência e à dicotomia sujeito-objeto (HARAWAY, 1995), em uma instituição universitária da Bahia, Brasil, a partir do trabalho de cortar plantas. Veremos aqui que, inacabados e incompletos, os significados e as identidades dos atores engajados em situações de pesquisas emergem imbricados em coletivos relacionais que garantem também os seus deslocamentos pelos diferentes espaços de produção, reunião e divulgação de conhecimentos botânicos.

Em um laboratório de botânica, o trabalho de fragmentar plantas para descrever as formas que as constituem e as multidões que habitam em suas partes tem menos a ver com a experiência da morte, que é inevitável no trabalho do biólogo - plantas, animais e outros seres precisam morrer para o trabalho seguir adiante -, do que com abertura do mundo para entes que a descrevem como diferença. Nesse processo, nomes e funções das plantas aparecem nas ciências biológicas relacionados a anatomias, morfologias e fisiologias, apresentadas de modo trans-situacional em um esforço de generalização das caraterísticas distintivas de todos os indivíduos de um determinado grupo taxonômico. Esses dados generalizáveis são produzidos em situações e lugares concretos e específicos que registram diferenças capturadas pelos biólogos-da-botânica². Se, por um lado, as generalizações permitem a constituição de um quadro conceitual em comunidades textuais compostas por livros, chaves de identificação botânica ${ }^{3}$ e outros textos; por outro lado, é, no trabalho prático e situado, que aparecem as excepcionalidades, as diferenças que multiplicam registros que informam modos de habitar o mundo com outras plantas, com animais e com outros entes. Plantas, animais, territórios e outros entes emergem como diferença no trabalho dos biólogos. Biomas, por exemplo, emergem como lugares excepcionais, como o bioma caatinga que emerge como excepcionalidade do Brasil em descrições de plantas e animais que marcam a Bahia também como diferença. Dito de outro modo, a caatinga é única no mundo porque plantas e animais produzem e atestam a sua excepcionalidade.

No trabalho prático e situado de cortar plantas, possibilitado por tecnologias como tesouras, ramificação das nervuras, vascularizações dos pecíolos e cromoplastos que compõem os vegetais aparecerem para o olhar especializado do biólogo-da-botânica, ao seu modo de ver, que é marcado pelo seu saber, marca as suas interpretações sobre o visto e estabelece um lugar no mundo (BERGER, 2000), aqui nas ciências biológicas. Tais estruturas informam as condições de possibilidade de existência de plantas em diferentes arranjos territoriais ${ }^{4}$. Essas mesmas plantas compõem as condições de possibilidade de existência para entes, humanos ou não, dos lugares onde habitam. As suas distribuições estão relacionadas às distribuições dos demais seres vivos que, com elas, tecem diversos modos de habitar.

Tomemos o exemplo das estruturas secretoras de plantas: elas produzem substâncias diferentes a depender do trabalho desenvolvido por humanos e não humanos pelos territórios e, por isso, são boas indicadoras das alterações dos lugares em que vivem. Essas estruturas podem alterar consonantemente os seus trabalhos, as suas ações, porque os ambientes estão sempre em processos 
de transformação. Quando os biólogos avaliam e estudam um ambiente para descrever impactos, eles convocam indicadores como as estruturas secretoras de plantas para que elas possam "dizer" algo sobre os territórios por elas habitados que passam a compor as suas descrições, os seus relatórios. Se pegarmos um relatório de impacto ambiental elaborado por um biólogo e lermos o papel das estruturas secretoras das plantas, interpretando-as a partir das formulações de Latour (2013) sobre o trabalho de tradução de redes em tecidos inteiriços de natureza e cultura, poderíamos considerar que tais estruturas que aparecem para serem vistas são: por demais sociais e narradas para serem produtos estritos da natureza; os empreendimentos que alteram a configuração de um território e, por conseguinte, o trabalho das estruturas secretoras, são cheios de fotossíntese e outras reações para serem reduzidos a poder e interesse; e os discursos do biólogo por demais reais e sociais para serem reduzidos a efeitos de sentidos estritamente botânicas. As plantas são, assim, circunscritas e circunscritivas dos territórios onde vivem. Elas são partes dos agenciamentos que produzem o social, o narrado e o natural.

Para os biólogos-da-botânica, o trabalho de cortar não significa um aniquilamento de folhas, caules, raízes e frutos, mas um investimento em retalhos que revelam formas que participam da produção dos territórios onde habitam. É uma experiência de composição, por multiplicação de formas, descrições dos mundos habitados pelas plantas em traçados das ciências biológicas - a botânica e as suas especialidades, como a taxonomia vegetal, a anatomia vegetal e a fisiologia vegetal. Dessa forma, os equipamentos relacionados ao trabalho de cortar são fundamentais para entender a agência dos biólogos-da-botânica, das plantas e demais entes não humanos com os quais se enredam, recuperando assim as condições de produção do social, do natural e dos discursos em agregados relacionais das ciências biológicas.

Neste artigo, trato do trabalho de cortar em situações práticos de um laboratório de botânica que investiga plantas da Bahia, Brasil. Ele é um desdobramento das notas de campo produzidas em uma etnografia desenvolvida entre os anos 2011 e 2016 que acompanhou, em cenários (laboratórios, matas e outros) relacionados às ciências biológicas da Universidade Estadual do Sudoeste da Bahia (UESB), movimentos de agregação de plantas, animais e biólogos em pesquisas voltadas para descrições da biodiversidade da região sudoeste da Bahia ${ }^{5}$ imbricadas às descrições de territórios.

Uma questão pode ser colocada frente a este cenário analítico: como tesouras, lupas e outros entes, envolvidos nas pesquisas sobre a biodiversidade enredam-se no trabalho de cortar do biólogo-da-botânica? A princípio, é possível inferir que os biólogos produzem e habitam territórios de produção de excepcionalidades (laboratórios, matas e herbários) por meio de microscópios, lupas, lâminas e muitas outros entes que permitem alcançar as perspectivas dos não humanos com os quais estabelecem relações estreitas, interpretá-las a partir de quadros de significados historicamente produzidos em seus agrupamentos (botânica, ecologia e zoologia, por exemplo) e colocá-las em circulação em suas comunidades textuais.

Para desenvolver a investigação que este texto retoma, imbriquei-me por laboratórios de biólogos, entrevistando-os e os observando em situações práticas de trabalho. Fui estudar as atividades no cotidiano do trabalho prático dos biólogos-da-botânica. Queria, por meio da etnografia (TSING, 2019; PEIRANO, 2014; STRATHERN, 2014; WAGNER, 2012), estar perto das realidades correntes de uma instituição de ensino e pesquisa para compreender as experiências práticas dos seus atores e suas interpretações/traduções sobre plantas e os territórios por elas habitados. Pretende-se, assim, produzir apontamentos etnográficos que possam contribuir com as circularidades dos discursos 
ambientais contemporâneos, atentos às relações de (e entre) humanos, não humanos e seus entornos (CAMARERO, 2017; SANTOS, 2014; MILTON, 1997).

Neste texto, territórios (biomas e laboratórios, por exemplo), agrupamentos científicos e outros entes são descritos em construção, fazendo-se em um mundo sempre aberto às múltiplas possibilidades de existência, mesmo em ruínas dos imperialismos industriais (TSING, 2019). Essas entidades negociam constantemente os mundos comuns, a exemplo de uma taxonomia, e disputam as interpretações, impondo as suas agendas na definição das ações dos coletivos em que se agregam.

\section{UM LABORATÓRIO DE BOTÂNICA E SEUS ENTORNOS}

Um corredor silencioso cheirando a formol repentinamente é invadido por vozes e risos que inventam outras ordens. No meio da tarde, chegam estudantes e abrem as portas das diversas salas onde estão organizados representantes da flora, coleções zoológicas, microscópios, lupas e muitos outros materiais. Cada uma dessas salas abriga um grupo em formação que compõe um ordenamento no primeiro piso do Módulo Amélia Barreto da Universidade Estadual do Sudoeste da Bahia (UESB), situada na cidade de Vitória da Conquista.

A arquitetura do prédio de laboratórios assemelha-se a outros espaços de confinamento (FOUCAULT, 2008), conforme também descreveu Marras (2009) em sua etnografia em laboratórios de biologia, genética e bioquímica. Ao entrar pela primeira vez em um prédio de laboratórios, somos surpreendidos pelo odor forte das substâncias utilizadas em diferentes experimentos. No caso aqui descrito, um silêncio fúnebre é rompido pelas vozes dos discentes quando se apresentam para aulas e pesquisas e pelos barulhos de todo aparato tecnológico, como geladeira e centrífuga.

No Módulo Amélia Barreto, há salas para plantas, salas para animais, salas para aparelhos tecnológicos. Há também humanos do lado de dentro, geralmente professores e seus orientandos. Tal ordem sintoniza-se com todo um movimento dos humanos que estão do lado de fora. Alguns carregam plantas, uns carregam armadilhas de captura de animais e outros carregam vidas retalhadas/multiplicadas em lâminas e lamínulas. Entram nas salas e começam a efetuar atividades práticas. Com o passar do tempo, formas são implodidas e novos arranjos são feitos com os mesmos entes, que migram de salas e colocam em formação uma nova aula ou protocolo de pesquisa. Estes movimentos produzem os laboratórios de ciências biológicas, dentre os quais se encontra o Laboratório de Botânica da descrição em tela.

Às segundas-feiras pela manhã, os professores das ciências biológicas chegam à UESB. Alguns se dirigem aos laboratórios e outros às salas de aula. Estes últimos, quando concluem as suas aulas, dirigem-se aos laboratórios para realizar e orientar atividades de pesquisa. Nos laboratórios há ainda: aulas práticas para turmas de graduação, orientações de iniciação científica (IC), orientações de trabalhos de conclusão de curso (TCC), orientações de atividades de monitoria de ensino e orientações de estágios. Os espaços físicos são divididos para comportar os gabinetes de trabalho, separando-os dos espaços usados para aulas práticas dos cursos de graduação e para realização de experimentos. Em muitas ocasiões, aulas e experimentos acontecem nos mesmos espaços e tempos. O som oriundo da parte em que as aulas são realizadas não respeita a divisória e invade os pequenos gabinetes onde os professores estudam e escrevem. 
Os biólogos que integram o corpo docente do Curso de Ciências Biológicas da UESB formaram-se em diversas instituições brasileiras e estrangeiras, ingressaram na Instituição para lecionar e, após o ingresso, passaram a desenvolver programas de pesquisa com plantas e animais locais. Conta-se que, além da diversidade de vidas não humanas em territórios da Bahia que interessam às ciências biológicas, as condições climáticas amenas, as diferentes paisagens, a conjuntura político-econômica, o acesso à saúde (clínicas e hospitais) e a presença de um aeroporto são atrativos para pesquisadores estabelecerem residência em Vitória da Conquista. Segundo os biólogos, este município é constituído por três biomas: caatinga, cerrado e mata atlântica. Por isso, seu território é por eles classificado como ecótono ${ }^{6}$.

Daqui por diante, passo a descrever uma expedição, realizada em junho de 2016 e relacionada a pesquisas do Laboratório de Botânica em uma área de mata da UESB, para coleta e descrição de plantas e, a partir dela, tento alinhavar dados produzidos em distintos momentos do trabalho de campo.

\section{EM BUSCA DE PLANTAS PARA O LABORATÓRIO}

Um podão - uma espécie de grande tesoura —, duas estudantes do Curso de Ciências Biológicas da UESB orientandas de iniciação científica da professora Cecília Oliveira de Azevedo ${ }^{7}$ e eu caminhamos por uma área de mata, pertencente ao Campus da UESB de Vitória da Conquista, em busca de plantas (ou suas partes) para o Laboratório de Botânica. As estudantes estavam interessadas em coletar exemplares de duas famílias de plantas (Malpighiaceae e Bignoniaceae) e eu em descrever as suas práticas. O local onde estivemos é conhecido como "Matinha da UESB" ou, simplesmente, "Matinha".

A minha participação na expedição como observador foi antecedida por um contato prévio com a professora Cecilia. Tudo devidamente planejado, apresentei-me no local às 8 horas do dia 8 de junho de 2016 e encontrei uma das estudantes na entrada do laboratório, esperando uma colega. Ela vestia calça, camiseta e uma blusa de mangas compridas, o que sinalizava a preparação para entrar em uma mata. Passado algum tempo, chegou outra integrante, apresentei-me, ela disse que Cecília já havia informado sobre a minha participação e abriu a porta do laboratório. Entramos no laboratório! Aguardando a movimentação das duas estudantes, pegando materiais como perneiras (proteções que são fixados nas pernas, sobre as calças, para protegê-las em áreas de mata), sacos plásticos e o podão, fiquei curioso sobre a utilidade daquela "tesoura" (do podão), sobre como ela agiria em campo. Naquele momento, soube que a expedição seria composta por três pessoas: as duas estudantes e eu.

Deslocamo-nos de carro até a entrada da Matinha e conversamos sobre a produção dos dados nas pesquisas por elas desenvolvidas. Elas disseram que as coletas são feitas duas vezes por mês, em duas expedições, uma pela borda e uma pelo núcleo da mata, buscando descrever a ocorrência de espécies das duas famílias de plantas que são alvos das suas investigações.

Quando chegamos à entrada da mata, elas ofereceram-me um par de perneiras para que eu protegesse minhas pernas de possíveis ataques de animais peçonhentos ou das plantas que poderiam cortar a roupa e a pele de maneira sutil (plantas também cortam). Elas vestiram também. Andar por matas exige cuidados com o deslocamento dos pés e com todo o corpo, exige uma habilidade corporal. E, mesmo com as proteções protocolares, percebemos as ranhuras na 
pele quando tomamos banho ao final do dia, quando a água do banho entra em contato com as regiões agredidas da epiderme.

Após vestirmos as perneiras, entramos na Matinha. Uma delas foi à frente e a outra atrás de mim, formamos fila de três membros na qual eu fui orientado, por meio de gestos, a ficar no meio. Elas falavam muito pouco, o que me deixava desconcertado. Perguntava-me: "Questiono algo sobre as suas pesquisas?". Tentava negociar a minha demanda de fala com os silêncios das estudantes-pesquisadoras-da-botânica. E assim foi em muitos momentos do trabalho de campo da minha pesquisa de tese. Com o passar dos anos, comecei a "escutar" os silêncios e os "dizeres" dos corpos dos biólogos e dos não humanos com os quais estabelecem relações de pesquisa. Aquelas estudantes guiavam-me, observavam-me e, certamente, produziram interpretações para também compreender o que eu fazia ao observá-las naquela mata. Eu observava e interpretava a mata e as estudantes-pesquisadoras e elas observavam-me, observavam a mata e nos interpretavam. Os estranhamentos entre observador e observado no trabalho de campo em antropologia foram exploradas por Wagner (2012) em sua abordagem inventiva da cultura, aquela que reivindica a inclusão do modo de vida do antropólogo (da sua cultura) em seu objeto de estudo. Os encontros etnográficos que tive em meu trabalho de campo permitiram o cruzamento de culturas diferentes, "choque cultural", elas mesmas assumidas como equivalentes ainda que a expressão da cultura observada, como entendimento inventado, aconteça aqui nos termos da cultura de um observador situado na intersecção entre as ciências biológicas e as ciências sociais. As experiências observadas e interpretadas/traduzidas jamais deixaram de lado o princípio da relatividade, a "relatividade cultural" (WAGNER, 2012), como um dos eixos do meu fazer etnográfico. Ou, como pontuou Merleau-Ponty (2012):

Pela ação da cultura, instalo-me em vidas que não são a minha, confronto-as, manifesto-as uma à outra, tornando-as compossíveis numa ordem de verdade, faço-me responsável por todas, suscito uma vida universal - assim como me instalo de vez no espaço pela presença viva e espessa de meu corpo (MERLEAU-PONTY, 2012, p. 152).

A trilha por onde caminhamos era estreita a ponto de andarmos agachados em alguns momentos e/ou retirarmos folhas e caules com ajuda de instrumentos como facão para seguir em frente. Em uma determinada altura, perdemo-nos, mas, logo, elas reencontram a trilha. Precisávamos ficar atentos aos sinais uns dos outros e aos sinais das plantas e dos animais da Matinha.

No início dos trabalhos de pesquisa das estudantes-pesquisadoras, uma equipe do Laboratório de Botânica avaliou que a antiga trilha, possivelmente aberta por outros pesquisadores - várias marcações e armadilhas para captura de animais deixadas no caminho indicavam isso - , necessitava ser "mais aberta", pois estavam se perdendo conforme disseram-me. Então, chamaram um mateiro que já conhecia o local e a trilha foi redesenhada seguindo os moldes da antiga para gerar o mínimo de impacto na área.

A realização de duas expedições mensais, uma pela borda e uma pelo núcleo, tem por objetivo abranger todo o fragmento, coletando amostras de espécies que vivem em duas posições distintas da mata. Viver em borda ou em núcleo de floresta exige comportamentos distintos que marcam a forma e o comportamento das plantas, ainda que pertençam a uma mesma espécie. Em uma viagem que fiz com os professores de outro laboratório para a mata atlântica, ouvi de um biólogo-da-ecologia que "árvores de borda são mais flexíveis do que árvores de núcleo para responderem melhor aos ventos que recebem". 
Para os biólogos, os seres vivos podem pertencer a uma mesma espécie porque seus indivíduos compartilham determinadas caraterísticas morfológicas e evolutivas, mas nunca são iguais, nunca são clones, eles são inovações. Movimentos de enformar emergem em contextos de relação constituídos em distintos territórios e, por conseguinte, o corpo de uma planta é a materialidade da sua própria relação no mundo, em um lugar e com o lugar. Ou seja, não é o ambiente que define a forma de uma planta, mas a sua constituição em um campo de relações situado, que é também situante. Assim, corpos de planta são produtos das suas expressões, e não apenas resultados dos seus genótipos. Fenótipo, por seu turno, é uma palavra que os biólogos usam para fazer referência aos movimentos de autoria de um corpo em relação com outros corpos pelos diversos lugares/territórios. A planta é sua espécie, é a sua família e é diferença que se difere no movimento de existência dos seus espécimes. Dançar não é um verbo exclusivo dos humanos (TSING, 2019), plantas também dançam melodias em coletivos relacionais.

Naquela quarta-feira de junho de 2016, em que nos encontramos no Laboratório de Botânica e caminhamos pela Matinha, a professora Cecília não nos acompanhou porque as suas alunas já tinham passado pelo processo de iniciação às expedições por campo (florestas e outras matas). Quando os estudantes candidatam-se a aprendizes de biólogos-da-botânica, Cecília realiza expedições de coleta e ensina os procedimentos necessários ao trabalho, podendo, eventualmente, repeti-las a depender das demandas dos estudantes.

Andamos por todo o trecho, mas as estudantes decidiram não coletar fragmentos de plantas de Malpighiaceae e Bignoniaceae porque não encontram flores, requisitos para a coleta. As flores são indicadores, mas não os únicos, dos vínculos às categorias taxonômicas. Na Matinha, soube que o podão (a "tesoura"), permitiria a coleta (o corte) de estruturas como folhas e flores em plantas altas sem precisar subir nelas.

Uma das estudantes marcou alguns espécimes que possivelmente pertenciam à família por ela investigada. Em expedições futuras, quando surgirem às flores, a estudante poderá confirmar, ou não, o vínculo taxonômico. A identificação começa no campo, no momento do encontro das plantas com as estudantes-pesquisadoras, a partir de sinais oferecidos pelas primeiras e alcançados pelo modo de ver das segundas. Perguntei às estudantes-pesquisadoras o que elas fazem quando encontram uma planta em condições de coleta e elas responderam:

- [...] a gente busca tirar algumas amostras para tentar prejudicar o mínimo, até mesmo porque a gente tem que ver se vai dar frutos depois. Então, a gente leva algumas amostras para passar por todo o processo de herborização.

- A gente toma todo um cuidado para não danificar muito a planta, né? Se têm flores, a gente não coleta todas as flores. A gente deixa para não causar danos. A gente vai precisar dela depois e ela [a planta] também vai precisar [da flor] mais que a gente. Disse a outra.

Durante as nossas conversas, surgiram assuntos acerca da relação entre estudantes-pesquisadoras e suas plantas que giraram em torno da perspectiva preservacionista orientadora das suas práticas em campo, evidenciada quando uma delas falou sobre a derrubada da mata para refazer a trilha: " [...] as pessoas veem as plantas como se elas não tivessem vida, porque elas ficam paradas, mas você sabe que elas têm. Você sabe que elas têm! Dá dó, sim, tá destruindo, tá...", disse a que nos guiava pela expedição. 
A relação entre os primeiros anos de sociabilidade e a escolha da taxonomia vegetal para dar forma a suas práticas de formação profissional surgiu em nossos diálogos. Para umas delas, as práticas da infância, convivendo com árvores frutíferas e hortas em casa e a identificação que teve com a disciplina morfologia vegetal, cursada na graduação em ciências biológicas, despertaram o seu interesse por plantas. Para a outra, a "curiosidade sobre as plantas" representa a motivação, pois não teve contatos frequentes com plantas em sua infância.

Frente a isso, é possível afirmar que as experiências primeiras podem ter desdobramentos na vida por fazer, mas isso não implica um fechamento da experiência adulta à infância como um jogo de causa-efeito (MERLEAU-PONTY, 2012). As estudantes não são meros objetos resultantes de uma organização familiar e das suas casas, mas cúmplices de arranjos porque estão imersas na condição de sujeitos em diversos coletivos, podendo vivenciar continuidades ou rompimentos com os apontamentos que constituem as tradições nas quais tecem suas trajetórias de vida e formação. Suas individualizações, inclusive nas ciências biológicas, são respostas às experiências de toda a vida, que também nutrem seus projetos. Vidas que não obedecem a um plano oculto, dado $a$ priori, que teria o desenvolvimento ontogenético como palco de emergência das capacidades originais; o que nos permite descrever acontecimentos de uma vida buscando as irregularidades do improviso que emergem como abertura criativa para distintas formas de existir: "improvisar é seguir os modos do mundo à medida que eles se desenrolam, e não conectar, em retrospecto, uma série de pontos já percorridos (INGOLD, 2012, p. 38).

Quis saber também sobre a "ocorrência", verbete que apareceu constantemente nas falas dos biólogos em quase todas as situações em que os observei e os entrevistei. Perguntei, sentado embaixo de uma árvore de grande copa, o que as plantas informavam e ambas responderam:

- A ocorrência...

- Às vezes, no nosso trabalho, a gente acaba identificando alguma planta que só ocorre na Bahia ou, então, que só ocorre em determinado município [...]. Disse uma delas.

- Ou até que não tinha ocorrido aqui. Porque a Matinha é pouco trabalhada e têm poucos trabalhos que já foram publicados sobre a Matinha. Então, é uma reserva que têm espécies... Por exemplo, no meu primeiro [trabalho], tinham muitas [espécies] que ainda não tinham sido descritas ocorrendo aqui na cidade. Então, isso indica que elas estão ocorrendo aqui. Por exemplo, se desmatarem à área e elas pararem de ocorrer, ficaria como se elas nunca tivessem ocorrido nesta cidade, ou até mesmo na Bahia [...]. No primeiro trabalho, teve caso de primeira ocorrência na Bahia. Então, ficaria acreditando que não ocorre tal espécie sendo que tá ocorrendo. Entendeu? É mais pra distribuição da espécie nas áreas. Retomou a que caminhava à frente.

- [...] eu tive dificuldade de encaixar uma planta do meu primeiro trabalho dentro de um gênero de Malpighiaceae, mas aí, inicialmente, eu acabei achando o gênero e o epíteto específico, que, no caso, vai dar o nome da espécie. Só que uma caraterística que estava na descrição não estava presente na planta que eu analisei. Então, essa planta está no herbário da UEFS [Universidade Estadual de Feira de Santana], ainda não está na coleção, mas está lá e, quando algum taxonomista da família de Malpighiaceae for visitar, poderá me ajudar nisso de saber se realmente é uma espécie nova ou se é realmente aquela que eu tinha colocado. Concluiu a que caminhava atrás na expedição. 
Os registros de ocorrência de plantas em um determinado território estão relacionados à existência de herbários como centro de organização de descrições de espécimes e espécies de plantas. Constituído de tantos outros lugares aos quais as suas coleções remetem, os herbários são inventários de plantas que, retalhadas e classificadas, possibilitam a salvaguarda e/ou produção das identidades de lugares, em termos das suas biodiversidades vegetais.

\section{HERBÁRIO E FORMAÇÃO DO TAXONOMISTA DE VEGETAIS}

Herbários são destinos dos exemplares de plantas transformadas em itens de coleção, as exsicatas ${ }^{8}$. Por isso oferecem aos pesquisadores considerados especialistas em determinados grupos de plantas possibilidades de continuar trabalhos iniciados por outros pesquisadores, incluindo estudos de revisão de descrições. Em cada trabalho de descrição ou revisão de táxon (espécie, gênero, família...), surgem novas descrições que geralmente ampliam o conhecimento sobre a diversidade de plantas que ocorrem em um determinado território. Esses espaços (também chamados de museus) contribuem com os fluxos de materiais (INGOLD, 2012) em discursos sobre a biodiversidade vegetal e, por conseguinte, dos territórios onde ocorrem.

Espécies e territórios produzem-se mutuamente na relação com pesquisadores de plantas em descrições que produzem uma consciência retrospectiva da biodiversidade vegetal, conforme também propôs Merleau-Ponty (2012) sobre a consciência retrospectiva da pintura em processos de transformação produzidos pela reunião das obras em um museu.

Segundo os biólogos que acompanhei, a destruição produzida por humanos é uma ameaça ao entendimento da biodiversidade porque causa extinção de espécies que poderiam descrever a biodiversidade dos lugares onde habitavam em um determinado fragmento do tempo. A extinção de espécies limitaria as possibilidades de cortar plantas e descrever movimentos de diferença de um determinado território em um determinado momento de sua existência.

- Ao fazer um estudo de uma determinada família de plantas, vocês acham que ele pode ajudar a descrever um território? Indaguei as minhas interlocutoras.

— Sim. [...] de levar o que a gente encontra aqui para a comunidade científica para que o conhecimento que se tem da área, da família, da distribuição. [...] as plantas são importantes na constituição das florestas [...]. Então, é importante para a comunidade científica ter conhecimento da ocorrência delas. Ponderou uma delas.

— E também da área toda, porque aqui, na Matinha, são poucos estudos que são realizados [...] Então, [esses estudos] chamam a atenção [dos pesquisadores] para área. Se ocorre uma espécie somente aqui, acaba dando mais atenção para essa área, uma atenção que hoje a gente não tem. Disse a outra.

A coleta é seguida por um intenso trabalho no laboratório, onde as plantas passam pelo processo de herborização ${ }^{9}$, descrição e identificação de estruturas como folhas e flores, utilizando lupa e chaves taxonômicas. Quando os exemplares coletados não se enquadram nas listagens de espécies já descritas, começam as expedições aos herbários para consultar as coleções da família investigada com o intuito de identificar se, em estudos anteriores, a planta em questão já havia sido descrita. Outra alternativa é o envio dessas plantas 
para especialistas das famílias às quais se vinculam para que eles concluam o trabalho.

A taxonomia vegetal é um trabalho tecido em redes de pesquisadores, laboratórios e herbários de distintas instituições e países. Ela pode envolver trabalhos relacionados a anatomia vegetal e genética vegetal, outras especialidades da botânica. Plantas são agrupadas por semelhança morfológica e por vínculos genealógicos estreitos, que estão intimamente relacionados, mas nunca num fechamento no qual filogenia é um efeito da ontogenia.

Retornando aos trabalhos de campo desenvolvidos pelo Laboratório de Botânica da UESB para fins de descrição de plantas, tomei conhecimento de uma expedição composta por biólogos-pesquisadores e seus orientandos (incluindo Cecília e suas orientandas) para coleta e estudos de/com plantas e animais no Parque do Espalhado no Município de Ibicoara, Bahia que foi interrompida devido às restrições financeiros da Instituição [UESB] e a um incêndio ocorrido naquela área. Na expedição, uma orientada de Cecília realizaria descrições de plantas de Malpighiaceae. Mesmo com a não realização do trabalho in loco, ele foi realizado em herbários. A estudante visitou herbários baianos, estudando as plantas coletadas por outros pesquisadores naquele território. $\mathrm{O}$ professor Avaldo Oliveira Soares Filho, curador do Herbário da UESB, Campus de Vitória da Conquista, na época, por exemplo, realizou coletas na área e a estudante teve a possibilidade de consultar a sua coleção.

Também as coletas realizadas pelos estudantes-pesquisadores de taxonomia vegetal durante as pesquisas de iniciação científica e de trabalho de conclusão de curso são enviadas para herbários. As duas estudantes que acompanhei na Matinha ainda não tinham definido, na ocasião do desenvolvimento da minha pesquisa de tese, para qual herbário as suas plantas seriam enviadas. As suas visitas aos herbários tiveram início em um trabalho anterior, quando investigavam as lianas (plantas de habito trepador). Elas viajaram por herbários situados em Salvador, Feira de Santana, Ilhéus e Vitória da Conquista, como também fez Cecília em sua formação nos herbários dos EUA e de países europeus. As plantas fluem nas coleções dos herbários constituindo condições de possibilidade de descrições (taxonomias) da biodiversidade vegetal de diversos lugares do planeta. Portanto, a formação do taxonomista de vegetais também deve acompanhar esses movimentos. Vejamos como aconteceu o movimento de formação de Cecília por esses espaços.

Ao ingressar na graduação, Cecília também vivenciou a sua formação em herbários. Ele realizou a sua iniciação científica no Herbário RADAMBRASIL, do IBGE. Lá, investigou taxonomia de orquídeas do Morro da Pioneira, na Serra da Jibóia, Bahia. Seu percurso para se tornar botânica especialista em taxonomia de orquídeas tem em uma Instituição fora da universidade o espaço para iniciação, para apropriação dos saberes necessários ao ingresso na botânica, explicitando que os agrupamentos científicos existem para além da universidade. Como uma das suas orientandas, Cecília disse que seu envolvimento inicial com as plantas aconteceu na infância, nos momentos em que pescava, "catava planta" e levava para cultivar em casa ${ }^{10}$.

Após conclusão do curso de graduação, Cecília foi para os EUA e se candidatou a voluntária no New York Botanical Garden Herbarium e regressou ao Brasil na véspera da seleção do Mestrado em Botânica da UEFS, concorreu e foi aprovada. Ingressou no Mestrado no ano de 2000 e investigou uma família de orquídeas do Parque Municipal de Mucugê, Bahia, Brasil. Ao final do curso, surgiu outra oportunidade para desenvolver um projeto no exterior: para cadastrar espécimes coletadas na região nordeste do Brasil e depositados no Royal Botanic Gardens, Kew, na Inglaterra. Ela antecipou a defesa da dis- 
sertação e foi novamente para o exterior, com bolsa, viagem que lhe permitiu iniciar a sua coleta de dados da pesquisa de doutorado. Cecília foi para a Europa com o projeto de tese já estruturado. Alguns pesquisadores do Jardim Botânico da Inglaterra desenvolviam trabalhos no Brasil e um deles (uma pesquisadora) propôs um projeto e queria estudantes-pesquisadores brasileiros no seu desenvolvimento. Cecília foi convidada para trabalhar na pesquisa, que não tinha relação com seu doutorado, mas, em sua carga horária semanal, havia um dia livre que ela usava para viajar para herbários e outras instituições de outros países da Europa, produzindo dados para o seu doutorado, seu "projeto pessoal". Em 2004, ela ficou na Europa e, em 2005, retornou para ingressar no doutorado. Para ela, aquele momento, assim como a experiência no Herbário de Nova Iorque, foi muito importante para a sua formação e para estabelecer contatos com pesquisadores.

Em seu mestrado, Cecília realizou coletas mensais durante um ano, descreveu e ilustrou a ocorrência de 32 espécies distribuídas em 22 gêneros de planta, sendo 11 espécies citadas pela primeira vez na literatura, em Mucugê, Bahia; comparou a ocorrência de famílias de orquídeas em áreas da Cadeia do Espinhaço, nos estados de Minas Gerais e Bahia, encontrando espécies exclusivas (AZEVEDO, 2004). No doutorado, Cecília fez estudo filogenético e revisão taxonômica de um gênero ${ }^{11}$ de orquídea terrestre de distribuição neotropical que ocorre entre a Flórida (Estados Unidos) e à Argentina, sendo a maior ocorrência no Brasil (AZEVEDO, 2009). O trabalho com orquídeas continuou após ingressar como professora da UESB, em 2008, por meio de concurso público, orientando pesquisas relacionadas a táxons da família de orquídeas e estudos de áreas. Com o passar dos anos, ampliou seus interesses por plantas de outras famílias, como as plantas de Malpighiaceae e Bignoniaceae.

No trabalho de coleta em campo, desenvolvido por Cecília e por suas orientandas, instrumentos como "podão" prolongam os seus corpos em direção às flores e frutos para cortá-los. As partes cortadas da planta seguem para o laboratório, onde são realizados outros procedimentos que podem envolver novos cortes. Instrumentos como podão permitem a realização do trabalho, é um agente ativo na ação de cortar um fragmento do mundo para descrever as excepcionalidades que habitam os territórios. Cortar plantas é uma ação assumida (LATOUR, 2012) pelos biólogos-da-botânica, ela é impulsionada por veículos, mediadores, que engendram outros mediadores desdobrando-se em situações novas e imprevistas

\section{PLANTAS E SEUS BIÓLOGOS: PERSPECTIVAS, AGENDAS E MODOS DE HABITAR}

Para descrever plantas, os biólogos-da-botânica ficam atentos às agendas dos não humanos, momentos decisivos das ações, um modo mais específico para fazer referência à agência dos não humanos, e reconhecem o papel destes no fluxo das suas pesquisas. Eles [os biólogos] precisam se aproximar das situações de existência dos espécimes de plantas que participam das suas pesquisas $\mathrm{e}$, para isso, vestem determinadas roupas para resistir às condições ambientais por eles suportadas, utilizam equipamentos (como o podão) que ampliam e modificam seus corpos, andam e produzem movimentos que permitem acessar os territórios habitados pelas plantas; e, a partir daí, iniciam processos de corte, que culminam em descrições sobre a distribuição de plantas pelos diversos territórios. 
Roupas, equipamentos e movimentos permitem que os biólogos estejam onde as plantas vivem - biomas, ecótonos e outras áreas, como a Matinha da UESB aqui descrita. Roupas, aparatos tecnológicos e biólogos compõem coletivos para agremiar outros entes, as plantas. Mas isso, apenas, não basta. Os biólogos-da-botânica ficam atentos aos cheiros, sons e cores das plantas e de outros habitantes das matas; eles são os catalizadores das primeiras interações, orientam e desencadeiam habilidades corporais para o trabalho de campo.

Biólogos-da-botânica são capazes de descreveras perspectivas das plantas que pesquisam ${ }^{12}$. As suas identidades e as das plantas são dadas pelos modos de habitar relacionados ao papel ecológico das espécies em comunidades bióticas, em lugares, que eles, ao se referirem às plantas e aos animais, chamam de nicho, formulação em constate elaboração nas ciências biológicas. Eles estudam espécimes quando precisam entender as suas distinções, as excepcionalidades situantes, na relação com os entes em um território, e, em última instância, o próprio território (estudos de área) como conjunto de condições que permitem a existência das espécies; e estudam espécies quando precisam entender excepcionalidades trans-situacionais expressas em espécimes de um determinado grupo taxonômico. A generalização trans-situacional é, por isso, sempre passível de um nova interpretação e reelaboração. As excepcionalidades encontradas em lugares específicos têm ascendência sobre as generalizações. ${ }^{13}$

O trabalho de campo é definidor do início e de todo o desenvolvimento das atividades dos biólogos em matas. No laboratório, eles vestem outras roupas, usam outros equipamentos (como lupas) e produzem outros movimentos, desta vez mais sutis e, geralmente, cortam as plantas em outros pequenos pedaços, que são tratados, descritos, traduzidos e armazenados. Ao retirar uma planta das condições ambientais necessárias à sua vida, ela pode não resistir e perder algumas propriedades anátomo-fisiológicas necessárias às descrições. Em determinados estudos, é necessário manter as condições mínimas dos locais de origem a fim de viabilizar a produção de determinados dados. Outros dados são produzidos em retalhos que já não possuem as mesmas propriedades da planta viva.

As habilidades manuais e os modos de ver exigem treinamento, eles são constantemente elaborados nas trajetórias de trabalho-formação, tendo os professores orientadores e as plantas como marcos importantes. No campo e no laboratório, há sempre contingências porque as agendas dos Outros com os quais os biólogos-da-botânica se relacionam são decisivas para as ações e, portanto, podem impedi-las ou autorizá-las. As práticas dos biólogos-da-botânica podem ser diversas e o desenvolvimento das habilidades manuais e a especialização dos seus modos de ver definem o foco de interesse dos seus programas específicos de pesquisa.

As descrições dos biólogos-da-botânica e os seus herbários certamente exigem uma rotina marcada pela continuidade ininterrupta do trabalho, sincronizado às agendas das plantas e dos demais não humanos com os quais se relacionam. Em muitos finais de semana, greves universitárias e feriados, encontrei-os com os seus orientandos executando protocolos de pesquisa. Em um final de semana específico (em um domingo), realizei observação na casa de um deles que, com as suas orientandas, não poderia dar pausa no trabalho que realizavam. As vidas dos biólogos-da-botânica reivindicam os cortes, em seus múltiplos sentidos, para sustentar as exigências das suas pesquisas.

Conforme vimos em páginas anteriores, os biólogos interpretam/ traduzem o habitar das plantas a partir das partes dos seus corpos, como folha, flor e fruto. Eles enunciam que estas estruturas são necessárias ao ciclo vital desses não humanos e alertam outros humanos para não entender a vida de uma planta com o mesmo referencial que interpretam a vida dos animais. Plantas 
aparecem para serem vistas em processo e, por isso, oferecem aos biólogos-da-botânica aberturas que, no caso aqui descrito, permitem cortes e vinculações taxonômicas em mãos habilidosas. E, como elas são um constante processo de tornar-se plantas, as suas taxonomias e os territórios a elas relacionados são também um constante vir-a-ser. A partir da perspectiva analítica de Ingold (2012), seria possível afirmar que plantas de Malpighiaceae e Bignoniaceae são lugares situados em outros lugares (biomas e matas) onde múltiplos aconteceres se entrelaçam e ainda:

Assim concebida, a coisa tem o caráter não de uma entidade fechada para o exterior, que se situa no e contra o mundo, mas de um nó cujos fios constituintes, longe de estarem nele contidos, deixam rastros e são capturados por outros fios noutros nós. Numa palavra, as coisas vazam, sempre transbordando das superfícies que se formam temporariamente em torno delas (INGOLD, 2012, p. 29).

Os biólogos-botânica acompanham as plantas tornando-se plantas (as suas aberturas no/para o mundo) e, por isso, são capazes de reunirem-se a elas, partilhando a experiência do habitar, condição necessária para descreveras perspectivas dos vegetais, em conexões parciais, sem que isto implique em mutações de biólogos em plantas e ainda seja possível prestar contas, como ensina a objetividade feminista de Haraway (2009), em coletivos multiespécie, nos termos de Tsing (2019). Ou seja, é capaz de descrever as perspectivas de um vegetal quem é capaz de comungar como ele a experiência de habitar um determinado lugar. Nesse ponto, penso ser preciso dizer que as perspectivas dos vegetais são elaborações constantes, e não um dado pronto a ser acessado por um sujeito em um espécime de planta. Quando os biólogos interagem com plantas e equipamentos, eles estão menos inspecionando os contornos que os separam do mundo do que se reunindo aos coletivos que dão origem as coisas e a si mesmos. Habitar o mundo, conforme propôs Ingold ${ }^{14}$ (2012), é juntar aos seus processos de formação, um mundo aberto que pode ser habitado devido à permeabilidade e conectividade das coisas vivas. Os equipamentos de laboratório, as plantas e os demais entes enredados nas descrições não são fatos consumados, eles são o seus "aconteceres". No movimento de habitar matas e laboratórios, vidas humanas e não humanas se cruzam e se articulam.

O nome que o taxonomista dá à planta e o seu registro de ocorrência em um determinado lugar marca a sua excepcionalidade, de espécies como registro de primeira ocorrência na taxonomia (excepcionalidade trans-situacional) ou de espécimes, representantes das espécies já catalogas pela taxonomia vegetal, como registro de ocorrência em um determinado lugar (excepcionalidade situacional). Os herbários têm fundamental destaque nesse processo, eles oferecem inventários sobre os quais se podem afirmar as excepcionalidades e colocam em circulação discursos, que devem ser entendidos como provisórios, parciais e constantemente reelaborados, a partir da reunião de plantas de muitos lugares do planeta, coletadas em expedições que retomam distintas temporalidades, inclusive aquelas relacionadas às colonizações das Américas, sendo possível retomar o passado, reinterpreta-lo e refazê-lo a cada nova investida de um taxonomista.

Merleau-Ponty (2012) tece uma fértil reflexão sobre a relação entre museus e pintura que possibilita entender também a relação entre herbários, plantas e botânica. Ele aponta o museu como o lugar da historicidade da morte e como imagem decaída da historicidade da vida do pintor. Com isso, para ele, a verdadeira história da pintura seria aquela "[...] que a coloca inteiramente no presente, habita os artistas e reintegra o pintor à fraternidade dos pintores" (MERLEAU-PONTY, 2012, p. 133). No caso aqui descrito, cada exsicata abre um horizonte de pesquisa, ela torna possível dizer algo sobre uma planta e o 
seu entorno antes dela. Ou seja, cada exsicata é constitutiva e transformadora do próprio herbário enquanto território que metaforiza a vida dos espécimes, conforme também concluiu Wagner (2012) sobre a metaforização da vida em cultura no museu. Nos herbários, acontece a metaforização dos espécimes em biodiversidade vegetal. As possibilidades de significações (como criação) dos territórios estão sempre abertas nos herbários. Por isso eles, como mostra das plantas de diferentes territórios, configuram-se, consequentemente também, como uma mostra dos lugares por elas habitados; permitem também que os biólogos estabeleçam relações com os territórios por meio das suas plantas. Situados na universidade e fora dela, eles produzem vazamentos de lugares, criando novas formas de entendimento deles mesmos nas descrições de plantas.

Esses dados permitem compreender que, nas ciências biológicas, a biodiversidade não é uma constância trans-situacional, ainda que seja assumida como um dado para fins práticos de pesquisa, mas um movimento de vir-a-ser, situante e relacional. Plantas e biomas são aqui entendidos como condição de possibilidade da experiência social, como Camarero (2017) assumiu o entendimento do mar em sua etnografia. Plantas e biomas poderiam também ser enunciados como trajetórias de movimento, séries temporais de vistas, oclusões e transições que se desdobram ao longo de incontáveis caminhos que levam de uma mata a outra, para dentro, para fora e para as suas fronteiras/transições (INGOLD, 2015). Biomas como caatinga, no Laboratório de Botânica aqui descrito, emergem como construção temporal, um conglomerado de cartografias de lugares, produto das ações das plantas, dos biólogos e de outros entes. Plantas e biólogos também são construções temporais, com tempos próprios que marcam os enredos dos coletivos aos quais estão relacionados. Biomas não seriam então uma soma das caraterísticas das plantas, mas criações elaboradas em contextos de relação que envolvem biólogos e outros não humanos, como tesoura, lupas, microscópios, chaves taxonômicas e outros entes.

Quando descrevem as ocorrências de plantas pelos diversos territórios, os biólogos descrevem o habitar (e os lugares) como processos de diferença que são registrados em herbários e divulgados em suas comunidades textuais. Essa relação entre o específico e o geral produz uma consciência retrospectiva da biodiversidade vegetal que circula em discursos de preservação que denunciam os usos humanos relacionados a empreendimentos como barragens, parques eólicos, mineradoras e outros.

\section{CONSIDERAÇÕES FINAIS}

Milton (1997), ao recuperar os percursos da antropologia ecológica/ ambiental, elabora uma comparação entre a diversidade biológica e a diversidade cultural e tece uma conclusão que estabelece regularidade de sentido com as interpretações/traduções feitas a partir dos materiais analíticos (discursos e práticas de equipamentos, biólogos e plantas) produzidas no escopo da pesquisa relacionada a este texto. Para Milton (1997), ambas (diversidades biológica e cultural) oportunizam a sobrevivência dos seres que as caracterizam. Então, se tomarmos a cultura como mecanismo de interação que sustenta a vida em coletivos relacionais, a sobrevivência humana dependeria da diversidade cultural.

Quero finalizar este texto tentando levar adiante a interpretação de Milton (1997): se aquilo que biólogos e outros humanos afirmam ser cultura e natureza fazem-se mutuamente de modo imbricado e com contornos borrados, a sobrevivência dos humanos e dos não humanos dependeria da manutenção dos processos constantes de produção das diversidades naturais e culturais, para além das dicotomias que as separam, ainda que os biólogos as assumam em 
propósitos práticos. A sobrevivência seria, então, resultado dos modos de produção de naturezas-culturas em coletivos de humanos e não humanos. Portanto, modos humanos de vida sustentáveis deverão diminuir as assimetrias que nos distanciam dos não humanos, reconhecendo-os como vidas que importam, para não despotencializar, ou mesmo cessar, os mecanismos geradores de diferenças. Não se trata de reafirmar uma "construção social da natureza" ou uma "naturalização do social", mas de recusar a separação entre humanidade e natureza, nos termos da formulação de Latour (2014, p. 12), que também recusa o determinismo da técnica sobre o humano - o materialismo - e o determinismo do humano sobre a técnica - o antropocentrismo (SANTAELLA; CARDOSO, 2015). Biólogos rejeitam ainda a separação entre indivíduo e seus entornos.

A recusa de tais dicotomias e o princípio de simetria entre as espécies e espécimes têm uma consequência crucial no entendimento dos biólogos: a negação da excepcionalidade da espécie humana. As interações (relações ecológicas nos ecossistemas) que produzem as vidas no presente são, assim, resultados de processos evolutivos, não como aprimoramento, mas como diversificação de formas de vida, que é por eles formulada como biodiversidade. No caso dos biólogos-da-botânica com os quais estabeleci interlocução, há a especificação (e especialização) biodiversidade vegetal. Biólogos podem afirmar, por exemplo, que um organismo como uma bactéria pode ser "mais adaptado" para viver um determinado ecossistema do que uma ave ou mamífero. Humanos não são mais ou menos evoluídos em relação a outras espécies. Para os biólogos, eles são espécimes de uma espécie situada em gênero. Durante todo o meu trabalho de campo, não ouvi os biólogos usarem o termo evolução como "melhora" ou "aprimoramento", mas como adaptação relacionada a uma área, um lugar. O que apareceu muito fortemente foi a indicação da preservação das espécies e das áreas a elas relacionadas, os seus entornos. Os textos produzidos pelos biólogos, a exemplo de relatórios de impacto ambiental, orientam a elaboração de políticas de manejo, reconhecendo as áreas estudadas como áreas de proteção ambiental a fim de preservar as espécies que nela habitam. Aqui não estou adentrando às exigências jurídicas do Estado Brasileiro para tipificar uma área como área de proteção ambiental. Estou mais atento às elaborações dos biólogos e, para eles, todas áreas devem receber atenção com vistas a preservar a biodiversidade que a constitui.

Áreas protegidas podem receber designações como parque, reserva ou refúgio. A ideia de parque, por exemplo, é problematizada por Santos (2014). Para ele, tal formulação admite a existência de um observador humano externo em relação a natureza, uma entidade que olha de fora a paisagem. As paisagens vistas por este observador hipotético não seriam produtos apenas "natural", mas construções que envolveriam também o trabalho dos humanos. No caso das plantas, quando os discursos sobre elas produzem apontamentos que se desdobram em definição de áreas (protegidas, ou não, pelo Estado), com todas as consequências das normatizações dos seus usos (políticas de manejo), já se produziria uma alteração "humana" na medida em que se tenta estabilizar um determinado momento de um território? Obviamente, esta estabilização é uma idealização irrealizável, mas que tem consequência nas interações e interpretações/traduções em/sobre um determinado território. A não intervenção não seria também um certo tipo de intervenção? A conservação seria aqui um tipo de produção do lugar a fim de garantir a continuidade de existências não humanas a ele relacionados; ela redefine a maneira com a qual os biólogos se relacionam com os territórios, levando-os a interrogar os seus próprios modos de vida individuais (locais) e coletivos (locais-globais). Em suma, ainda que os discursos dos biólogos, e não apenas dos biólogos-da-botânica, façam transitar sentidos que parecem estar sustentados na dicotomia humanidade-natureza, as 
suas próprias interações com as plantas e com os animais não humanos parecem não reconhecer tal dicotomia.

Nas ciências biológicas, discursos sobre a biodiversidade sustentam preocupação sobre a natureza, reúnem biólogos com distintos modos de ver (botânicos, ecólogos, geneticistas, zoólogos...) e distintas habilidades manuais (corporais) em torno de algo comum: a diversidade da existência. Tal enunciado agremia também não especialistas, tem efeito persuasivo para além das ciências biológicas e institui os biólogos como sujeitos produtores de discursos que informam a consciência retrospectiva da biodiversidade e indicam as ações globais de manejo sustentável das diversas áreas do planeta, em diversos lugares. Discursos e orientações práticas sobre manejo produzidos pelos biólogos esbarram em interesses mais amplos relacionados às diversas disputas pelo espaço - Ingold (2005) possivelmente rejeitaria o uso deste verbete, mas eu o mantenho devido a sua força persuasiva e familiar na composição "disputas pelo espaço". No caso dos territórios relacionados aos trabalhos dos biólogos que acompanhei, os interesses de mineradoras, parques eólicos, barragens (de água e rejeitos), agronegócio... miram em outros elementos persuasivos, como a geração de emprego e "renda". Todos parecem reconhecer a legitimidade dos discursos e das orientações dos biólogos como também dos interesses daquilo que, no Brasil, se convencionou a chamar de "mercado" e/ou "desenvolvimento", não sem experimentar o mal-estar de viver em um mundo de assimetrias que hierarquizam as vidas, umas importam mais, outras menos; plantas e outros não humanos ficam sempre em desvantagem nas lógicas globais do "mercado" e do "desenvolvimento", são recursos a serem explorados. Também humanos e não humanos atingidos por barragens de rejeitos de mineração têm suas vidas reféns dos riscos e da morte em um país [o Brasil] onde duas barragens de rejeito romperam em um curtíssimo intervalo de tempo, nos municípios de Mariana (em 2015) e Brumadinho (em 2019) em Minhas Gerais.

Há uma imensa pauta de interpretação sobre os discursos ambientais contemporâneos ainda em aberto e conteúdos etnográficos poderão contribuir com a feituras de lugares por vir, nos quais a existência da espécie humana não possui uma total garantia. Os biólogos sabem disso e sabem também que outras espécies, muitas delas subestimadas pelos projetos desenvolvimentistas dos humanos, sobreviverão a possíveis fins do mundo e imporão as suas agendas. Discursos preservacionistas produzidos pelos biólogos parecem tentar também garantir a existência de todos ao vindicar a estabilização do presente etnográfico das suas descrições.

Plantas e seus biólogos rompem com interpretações deterministas, não para abandonar a agência dos territórios (mata, floresta, laboratórios, herbários e outros) na produção das experiências sociais, mas para entendê-los como produtos de coletivos relacionais constantemente mutáveis e temporais, povoados por naturezas, políticas, economias, discursos e culturas. Biólogos-da-botânica cortam plantas para reunirem-se (habitar com) a elas e descrever perspectivas que informam experiências de produção de diferenças nas ciências biológicas.

\section{NOTAS}

${ }^{1}$ Versão revisada de parte da tese de doutorado intitulada "Plantas, animais, biólogos e outros entes na caatinga: notas etnográficas em mundos de areia", desenvolvida junto ao Programa de Pós-Graduação em Ciências Sociais da Universidade Federal da Bahia sob as orientações das professoras Iara Maria de Almeida Souza e Núbia Regina Moreira. Para a elaboração deste texto, foram mobilizados materiais analíticos (entrevistas e observações) produzidos entre biólogos-da-botânica da Universidade Estadual do Sudoeste da Bahia com apoio da Universidade do Estado da Bahia (UNEB) e da Fundação 
de Amparo à Pesquisa do Estado de Bahia (FAPESB). No processo de revisão e ajuste dos argumentos, dialoguei com os pesquisadores Eleuza Diana Almeida Tavares, João Maurício Santana Ramos e Maria Eunice Limoeiro Borja.

${ }^{2}$ Uso a expressão biólogo-da-botânica, em vez de, simplesmente, biólogo ou botânico, porque essa foi a forma de tratamento que o coletivo de biólogos com quem estabeleci relação utilizava para fazer referência aos biólogos que pesquisam plantas e com plantas.

${ }^{3}$ Chaves de identificação botânica são textos que apresentam conjuntos de elementos de identificação mobilizados pelos biólogos-da-botânica ao agrupar plantas em grupos taxonômicos de uma determinada região ecológica/geográfica.

4 Uso aqui os termos "território" e "lugar" como sinônimos. O biólogos que estabeleceram interlocução comigo usam também o termo "área" para se referirem aos lugares (territórios) em que realizam os seus trabalhos de campo. Uma pauta sobre a discussão do lugar em uma perspectiva decolonial (ESCOBAR, 2005) surgiu em meus últimos investimentos de pesquisas na caatinga e será explicitada em publicações posteriores.

${ }^{5}$ A Bahia é um dos vinte e seis estados do Brasil. Até os anos 2000, o Governo da Bahia agrupava os seus municípios em regiões com base em caraterísticas econômicas, a "região sudoeste" era uma delas. Ainda que essa divisão tenha se tornado institucionalmente obsoleta, ela ainda é utilizada pelos seus moradores.

${ }^{6}$ Área de transição ambiental entre duas comunidades, apresentando variações da vegetação e das populações de animais. As fronteiras, nos termos de Haraway (2009), são gerativas de significados e corpos.

${ }^{7}$ Todos os nomes de professores do Curso de Ciências Biológicas que estabeleceram interlocução comigo e que aparecem nos textos produzidos a partir da minha pesquisa de tese são reais. Em consonância com Despret (2011), tentei não produzir "efeito sem nome", aquele fundado em uma relação assimétrica que distribui poder equivocadamente. Isso se deveu a uma tentativa de produzir dados sobre projetos de distinção de professores universitários das ciências biológicas em territórios de fronteira caatinga-cerrado-mata atlântica que agregasse valor (histórico?) a ciências regionalmente situadas. No entanto, o "anonimato" sempre esteve no conjunto das possibilidades dadas nos encontros de interlocução e nas decisões deles decorrentes. O "efeito sem nome" apareceu, como na formulação "estudantes-pesquisadoras", para fazer referência aos atores que não tive como manter interlocuções duradouras e necessárias ao detalhamento dos seus projetos.

${ }^{8}$ Planta transformada em peça de coleção de um herbário.

${ }^{9}$ Processo que envolve manuseio de plantas para transformá-las em entidades aptas a habitar em um herbário.

${ }^{10}$ Cecília é neta de Thales de Azevedo, antropólogo e médico baiano falecido em 1995.

Trabalho de retomada das descrições para identificar se as espécies estão corretamente vinculadas a um determinado gênero e/ou se há espécies que pertencem a um determinado gênero e não foram vinculadas a ele no momento da sua determinação. Para um biólogo-da-botânica, é sempre possível retomar uma revisão taxonômica, sobretudo, a partir de técnicas moleculares que permitem uma "entrada" no genoma de plantas. Agora não apenas flores, folhas e frutos são indicadores de relações de parentescos de espécies em um mesmo gênero, mas também o genoma das plantas.

${ }^{11}$ A noção indígena de "ponto de vista", descrita por Viveiros de Castro (1996) e Lima (1996) na formulação do "perspectivismo ameríndio", das cosmologias amazônicas, parece ser uma fértil possibilidade para pensar as agendas dos não humanos, aqui especificamente, a das plantas. No entanto, há distanciamentos marcantes, um deles é o entendimento da humanidade. Para os ameríndios, a humanidade é a condição original comum ente humanos e animais não humanos e, para os biólogos, o humano é uma derivação em um determinado grupo de animais (Gênero Homo), conforme a perspectiva evolucionista.

${ }^{12}$ No meu movimento de interpretação/tradução das práticas dos biólogos, fico muito tentando a identificar correspondência entre, de um lado, habilidades manuais e modos de ver e, de outro lado, método e quadro referencial da botânica, respectivamente. Uma espécie de "essencialíssimo positivista" para todos os fins práticos em um laboratório.

${ }^{13}$ Ingold (2012) critica as noções de "objeto" e "rede" da teoria do ator-rede (ANT), especificamente as apropriações e traduções do francês para o inglês, por reproduzir a 
divisão metafisica entre sujeitos e objetos que, para ele, atribui ao segundos [aos objetos] uma agência fetichizada e propõe um "mundo sem objetos" (ASO). A sua proposta consistiria em deslocar a discussão da agência para a vida das coisas, não dos objetos, o que deslocaria também a abordagem da materialidade para os fluxos de materiais, com consequência no modo de ler a criatividade das coisas: enquanto reunião improvisada, não como objetos acabados. Práticas improvisadas seriam linhas ao logo das quais as coisas são formadas, que ele formula como malha (meshwork), diferente de conexões como em uma rede. Latour (2012), por sua vez, entende a rede uma ferramenta analítica que indica aquilo que poder ser mapeado, e não como algo já mapeado, o que parece não destoar muito da noção de malha. Quanto a mim, estou menos interessado em possíveis contrapontos entre ambos, que são persuasivos e formativos, do que em mobilizá-los em minhas interpretações sobre o problema da agência nas ciências biológicas.

\section{REFERÊNCIAS}

AZEVEDO, Cecília Oliveira. Filogenia e revisão taxonômica do gênero PrescottiaLindl. (Orchidaceae - Orchidoideae). Tese. (Doutorado em Botânica) - Departamento de Ciências Biológicas, Universidade Estadual de Feira de Santana, Feira de Santana, Bahia, 2009.

AZEVEDO, Cecília Oliveira. A Família Orchidaceae no Parque Municipal de Mucugê, Bahia, Brasil. Dissertação. (Mestrado em Botânica) - Departamento de Ciências Biológicas, Universidade Estadual de Feira de Santana, Feira de Santana, Bahia, 2004.

BERGER, John. Modos de ver. Barcelona/ES: Editorial Gustavo Gili, SL, 2000.

CAMARERO, Leticia D'Ambrosio.La Experimentación Perceptual de la Costa y el Mar: un estudiocon surfistas, biologos y pescadores artesanales. Tessituras, Pelotas, v. 5, n. 1, p. 29- 55, jan./jun. 2017.

DESPRET, Vinciane. Leitura etnopsicológica do segredo. Fractal, Rev. Psicol., Rio de Janeiro, v. 23, n. 1, p. 05-28, abr. 2011.

ESCOBAR, Arturo. O lugar da natureza e a natureza do lugar: globalização ou pós-desenvolvimento? In: LANDER, Edgardo (org.). A colonialidade do saber: eurocentrismo e ciências sociais. Perspectivas latino-americanas. (CollecciónSurSur). Ciudad Autónoma de Buenos Aires: CLACSO, p. 133-168, 2005.

FOUCAULT, Michel. Vigiar e punir: nascimento da prisão. Petrópolis: Vozes, 2008.

HARAWAY, Donna. Saberes localizados: a questão da ciência para o feminismo e o privilégio da perspectiva parcial. Cadernos Pagu, n. 5, p. 7-41, jan. 2009.

INGOLD, Tim. Estar Vivo: ensaios sobre movimento, conhecimento e descrição. Petrópolis, RJ: Vozes, 2015.

. Trazendo as coisas de volta à vida: emaranhados criativos num mundo de materiais. Horiz. antropol., Porto Alegre, v. 18, n. 37, jun. 2012.

KIRKSEY, S. Eben; HELMREICH, Stefan. The emergence of multispecies ethnography. Cultural Anthropology, v. 25, n. 4, p. 545-576, out. 2010.

LATOUR, Bruno. Reagregando o social: uma Introdução à Teoria do Ator-Rede. Salvador: Edufba, 2012.

LIMA, Tânia Stolze. O dois e seu múltiplo: reflexões sobre o perspectivismo em uma cosmologia tupi. Mana, Rio de Janeiro, v. 2, n. 2, p. 21-47, out. 1996.

MARRAS, Stelio. Recintos e evolução: capítulo de antropologia da ciência e da modernidade. Tese. (Doutorado em Antropologia) - Departamento de Antropologia, Universidade de São Paulo, São Paulo, 2009.

MERLEU-PONTY, Maurice. A linguagem indireta. In: A prosa do mundo. São Paulo: Cosac Naif, 2012. 
MILTON, Kay. Ecologías: antropología, cultura y entorno. Revista Internacional de Ciencias Sociales, v. 154, p. 86-115, 1997.

PEIRANO, Mariza. Etnografia não é método. Horiz. antropol., Porto Alegre, v. 20, n. 42, p. 377-391, dez. 2014.

SANTOS, Carlos. Naturalismos y acumulación por desposesión: paradojas del desarrollo sustentable. Horiz. antropol., Porto Alegre, v. 20, n. 41, p. 331356, jun. 2014.

SANTAELLA, Lucia; CARDOSO, Tarcísio, O desconcertante conceito de mediação técnica em Bruno Latour. Matrizes [enlinea], São Paulo, n. 1, v. 9, p. 167-185, jan./jun. 2015.

STRATHERN, Marilyn. O efeito etnográfico. In: O efeito etnográfico. São Paulo: Cosac Naify, 2014.

TSING, Anna Lowenhaupt. Viver nas ruínas: paisagens multiespécies no Antropoceno. Brasília: IEB Mil Folhas, 2019.

VIVEIROS DE CASTRO, Eduardo. Os pronomes cosmológicos e o perspectivismo ameríndio. Mana, Rio de Janeiro, v. 2, n. 2, p. 115-144, out. 1996.

WAGNER, Roy. A invenção da cultura. São Paulo: Cosac Naify, 2012.

SUBMETIDO EM: 17/03/2019.

APROVADO EM: 18/09/2019. 